\title{
Energy-Efficient Design of a Research Greenhouse with Modelica
}

\author{
Dipl.-Ing. Torsten Schwan ${ }^{1} \quad$ Dipl.-Ing. René Unger ${ }^{1} \quad$ B.A. Jörg Pipiorke ${ }^{2}$ \\ ${ }^{1}$ EA Systems Dresden GmbH, Germany, \{torsten. schwan, rene. unger \} @ea-energie. de \\ ${ }^{2}$ ITI GmbH, Germany, pipiorkeditisim.com
}

\begin{abstract}
Greenhouses, especially for research applications, have high requirements on indoor climate control. The technical systems for heating, cooling, and moistening are more complex than in typical dwelling houses or office blocks and are highly dependent on local weather conditions. Increasing the energy efficiency and integrating renewable power into these systems is a sophisticated engineering task which requires extensive investigation.

This paper describes a combined approach to model and simulate building operation and HVAC system behavior of a research greenhouse with Modelica. This includes the presentation of some important modelling paradigms as well as system concept validation with some interesting simulation results.
\end{abstract}

Keywords: Green Building, Building Simulation, Solar Cooling, Greenhouse Design

\section{Introduction}

Greenhouses are used to cultivate a great variety of plants from all over the world during the whole year. Therefore indoor temperature and humidity have to be controlled at a certain plant-specific level regardless of environmental conditions. Furthermore, the cultivation of plants requires a sufficient amount of light. This way, greenhouses are built with excessive glass surfaces to optimally use solar radiation for the required lighting. However, buildings with large glass surfaces often overheat especially during summer time. To ensure a sufficient indoor temperature level even in times of high solar input and without losing humidity, this building type requires huge amounts of cooling energy which has to be provided by the building internal HVAC (i.e. Heating, Ventilation, Air Conditioning) system.

An optimal HVAC system design for greenhouses requires extensive analysis. Besides building physics (e.g. heat losses through walls and windows, ventilation) required plant-specific indoor temperature and humidity as well as solar radiation level highly affect heating and cooling system requirements. Furthermore, increasing energy prizes and today's demands for environmental protection require alternative system solutions. To reduce running costs as well as ecological footprint a suitable combination of local renewable energy production, highly efficient building materials, and intelligent control algorithms is needed.

A multi-domain system simulation helps to consider all these aspects in one evaluation and optimization framework. This paper describes how SimulationX and the Modelica-based Green Building library were used to analyze, to evaluate, and to validate an innovative approach of greenhouse HVAC system design. Because main overall energy consumption of a greenhouse is used for cooling, the presented work mainly considers cooling energy system design.

The key concept is the usage of solar heat for indoor cooling, since the cooling system is mostly needed when it is sunny. Therefore, an absorption cooling machine supplied by two different types of solar thermal collectors and district heating is used to generate the required cooling energy.

The simulation approach is basically divided into two parts. The initial simulation of building physics and operation is followed by an accurate simulation of HVAC system behavior including optimized system control algorithms.

This paper gives an overview about some interesting aspects of building operation and HVAC system modeling. It presents a short description of the developed greenhouse building physics model including all inner loads, like assimilation lighting and humidification, as well as required control algorithms for lighting, shading and temperature control. Special emphasis is put on the identification and modelling of suitable parameters representing plant growth which is necessary to model indoor humidity behavior.

Furthermore, the contribution presents how to model the designed HVAC system with Green Building library components. Additionally necessary extensions of library components are presented. Finally, the paper compares some interesting results regarding parameter variation and adapted system configurations.

\section{Building and HVAC System Concept}

The planned greenhouse will be built in the city center of Leipzig, a major city in Eastern Germany. As a center of biological research, scientists and students of University of Leipzig will use it to identify and evaluate effects of global warming on indigenous 


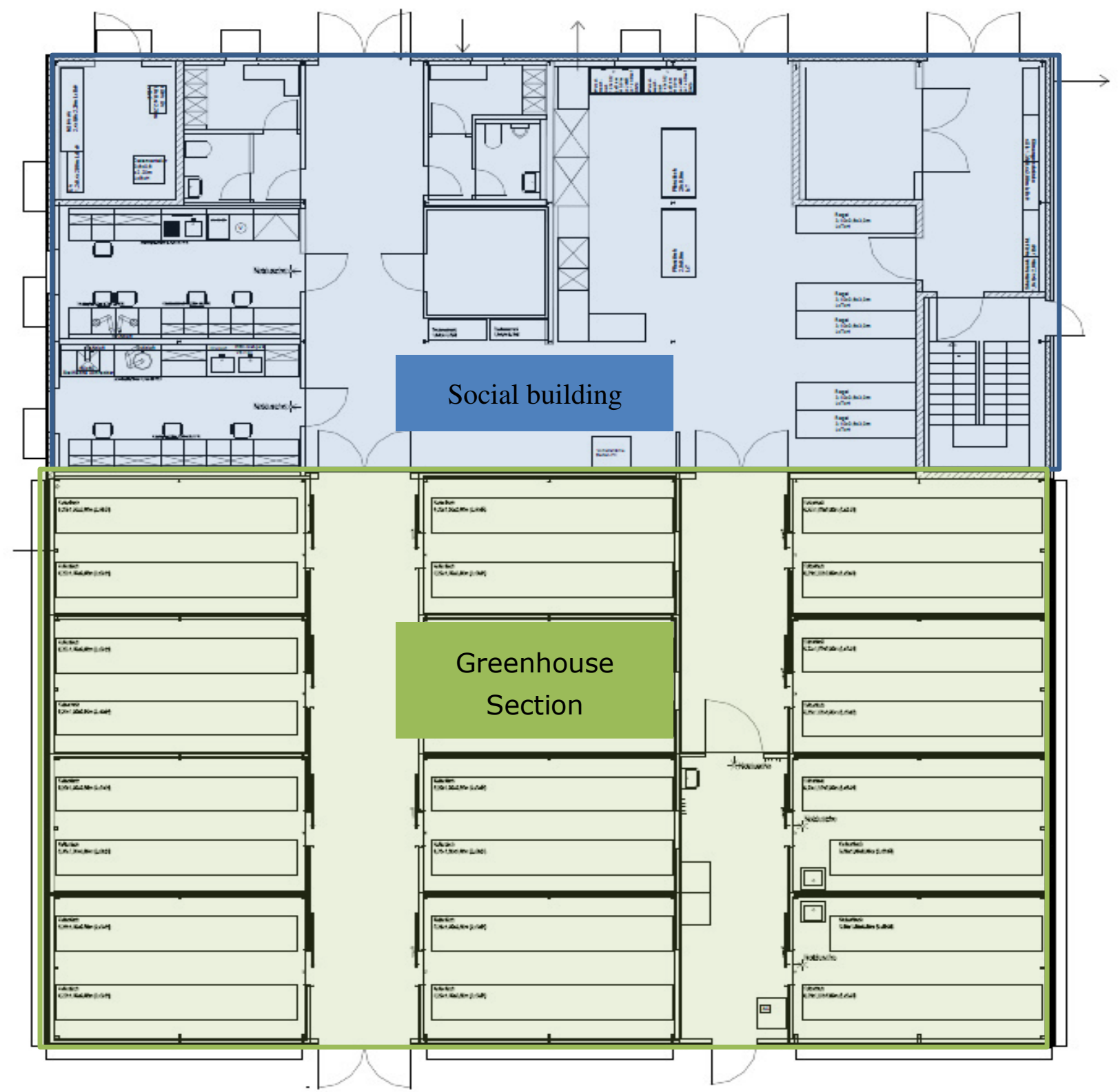

Figure 1: Floor plan of greenhouse section and social building (GEFOMA, 2015)

vegetation, and to perform further research-relevant experiments.

The planned building basically consists of a solid social building with basement and first floor as well as a glass-covered greenhouse section with an overall basic area of about $1.000 \mathrm{~m}^{2}$. The greenhouse is divided into twelve cubicles to cultivate twelve different plant species at the same time. Temperature and humidity control thus require individual settings in each cubicle.

Planner's basic idea was to reduce the overall ecological footprint about $50 \%$ in comparison to a conventional greenhouse concept. This way, two different types of the building had to be compared regarding heat, cold and electricity demand.

Both building concepts, reference and alternative, mainly differ regarding greenhouse section construction as well as planned HVAC system. Basically, the alternative greenhouse section construction substitutes single with insulating glazing. Furthermore, each glass surface in each cubicle can be shaded individually by a two-part shading system.

Temperature and humidity control is supported by a mechanical ventilation system using automatic tophung windows in the roof ridge.

The planned HVAC system is divided into heating and cooling systems. Instead of a conventional oil-fired condensing boiler the alternative building uses locally available district heating as heat supply. This is a comparatively simple and energy-efficient but not that innovative solution.

Real innovation is planned regarding cooling system design. The reference building uses a chilled water unit cascade with dry chillers as cold supply. Opposite to 


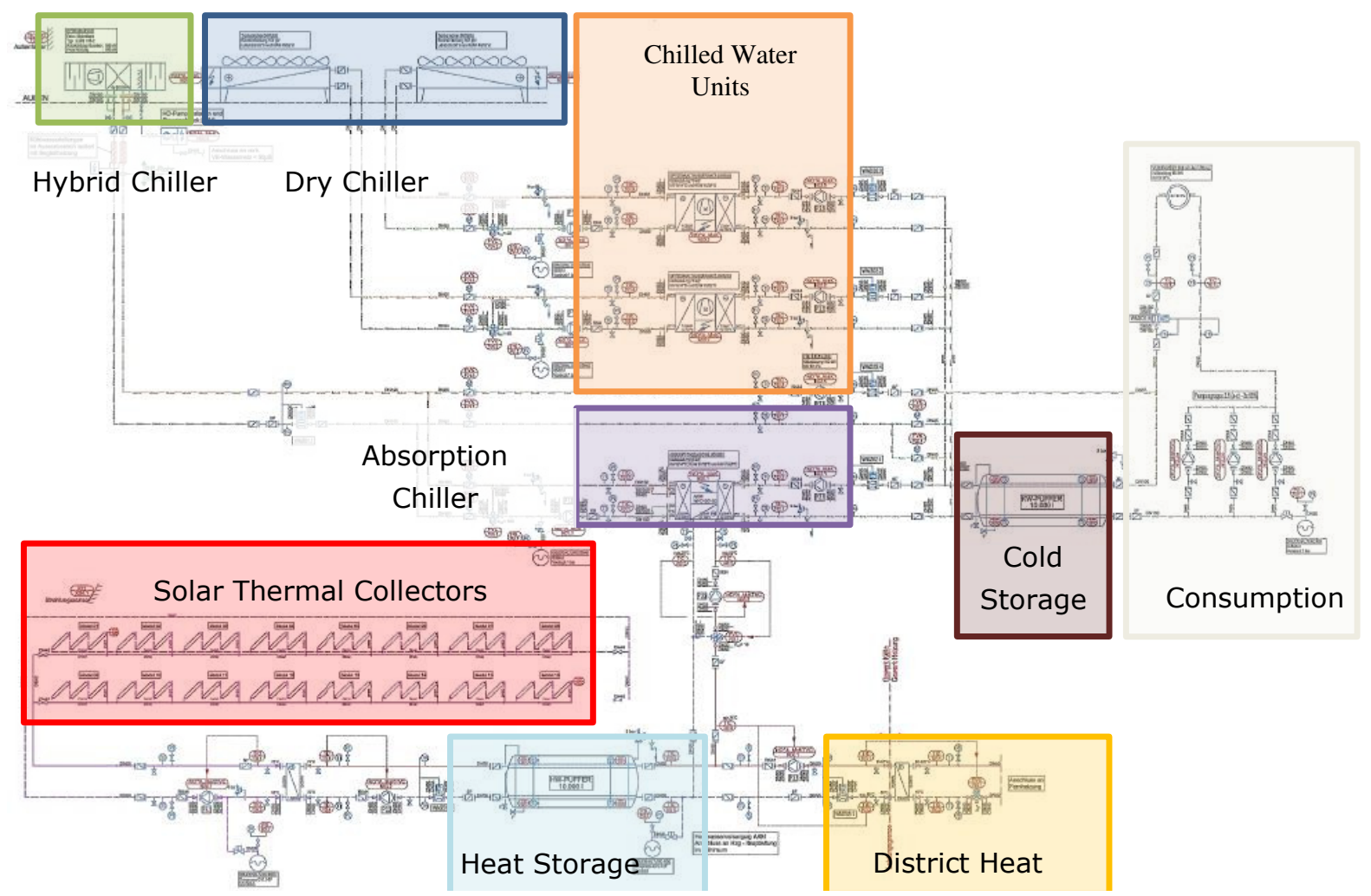

Figure 2: HVAC system concept (GEFOMA, 2015)

that, the alternative cooling system is based on an absorption chiller. This uses solar thermal collectors for heat source with district heating as backup. Furthermore, a small cascade of chilled water units provides peak cooling power in times of higher cooling demand.

Because of low required recooling temperatures (maximum $32^{\circ} \mathrm{C}$ even at ambient temperatures of $35^{\circ} \mathrm{C}$ ) the absorption chiller uses a hybrid cooler as heat exchanger. Hybrid chillers provide lower recooling temperatures by additional cooling with latent heat of water evaporation.

As an extended research topic two different types of solar thermal collectors, direct flow and heat pipe, are integrated in the presented HVAC system concept. The collector surface area is evenly distributed between the two systems. Both collector systems have advantages and disadvantages at different operation points. This way, simulated solar gains will be compared to later measurements in a subsequent monitoring campaign after building completion.

Furthermore, greenhouses often require cooling energy even when ambient temperature is comparatively low, e.g. sunny winter days. In this case, dry and hybrid chillers can directly provide cooling energy without further use of electricity (Chilled Water Units) or heat (absorption chiller), i.e. free cooling. Because hybrid chillers produce lower recooling temperatures at same ambient temperature level, presented HVAC system concept prefers this system to provide free cooling. This way, free cooling is possible to $10^{\circ} \mathrm{C}$ ambient temperature and $55 \%$ relative humidity.

\section{Building Operation}

Greenhouses widely differ from normal buildings. Besides excessive glass surfaces and extended control algorithms for window shading, heating and ventilation the cultivation of different plant species requires specific levels of indoor temperature and humidity. This way, building simulation has to put special emphasis on indoor climate. The calculation of inner heat gains by persons or electric components is not suitable anymore. Furthermore, greenhouses mainly require cooling energy. Cooling load calculation is a complex task by itself (VDI, 2007).

Basically, characteristics of cultivated plant species have major influences on resulting building behavior. They are mainly responsible for all relevant hygrothermal requirements in each cubicle, like indoor temperature, lighting, and humidity.

To include these major influencing characteristics into the simulation, a set of suitable plant characteristics have to be identified. The basic idea is to find one or two plant species with an average behavior of plants based on the following parameters:

- Indoor temperature (day and night),

- Relative humidity,

- Light intensity and illumination duration,

- Duration of measurement, and

- Plant transpiration. 
These characteristics were scrutinized together with the specialists of University of Leipzig, the desired building operator. This way, two different kinds of parameter sets could be identified:

1. Global climate change on root characteristics:
a. $15^{\circ} \mathrm{C} / 18^{\circ} \mathrm{C}$ by day, $8^{\circ} \mathrm{C}$ by night
b. $50 \%$ relative humidity
c. $1000 \mathrm{~lx}$ light intensity during $16 \mathrm{~h}$ per day
d. 4 months measurement

2. Underground and aboveground germination:
a. $22^{\circ} \mathrm{C}$ by day, $15^{\circ} \mathrm{C}$ by night
b. $60 \%$ relative humidity
c. $10.000 \mathrm{~lx}$ light intensity during $16 \mathrm{~h}$ per day
d. 3 months measurement

These characteristics adequately describe building requirements regarding lighting and indoor temperature. Apparently, the University of Leipzig will mainly use the greenhouse to cultivate indigenous plant species. That way, cooling energy demand will be comparatively high during summer time.

Together with indoor temperature, the relative humidity describes the hygrothermal reference behavior in each cubicle. However, the definition of a desired humidity set point is not sufficient to define relevant requirements to ventilation and humidification system. The transpiration of plants as a major influence on moisture is missing.

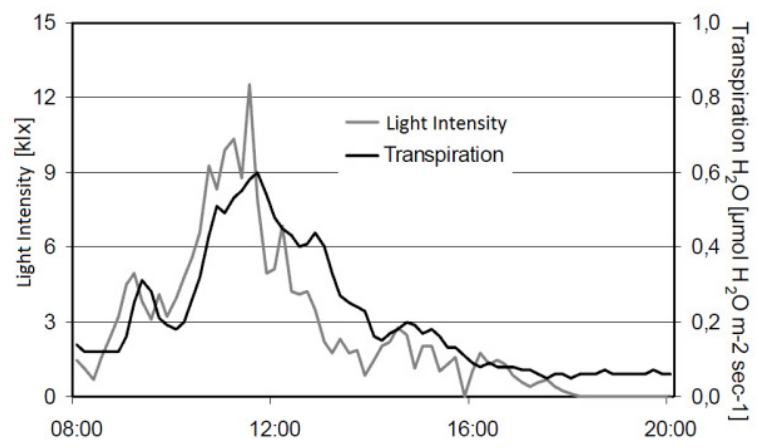

Figure 3: Correlation between light intensity and transpiration for a specific plant species (Bertram et. al., 2004)

To model the transpiration of plants the simple correlation between light intensity and transpiration was used (c.f. Figure 3). This way, values between 0.028 and $0.4378 \frac{\mathrm{mg}}{\mathrm{m}^{2} \mathrm{~s}} / \frac{\mathrm{W}}{\mathrm{m}^{2}}$ could be identified for different relevant plant species as additional model input parameters.

\section{Green Building Library}

The building and HVAC system were modeled using SimulationX and the Green Building library. This library was developed by EA Systems as a versatile simulation environment for renewable energy systems and energy management design (c.f. Schwan et. al., 2012). By adapting an approach widely used in the automotive industry, several elements for the production of renewable energy and heating systems were created as well as storages and electrical or thermal consumers. Most of the models represent real world objects like vehicles, electrical inverters or valves. Granularity and complexity of each element are thus in the same range while preserving a flexible yet easy modeling process (i.e. physical as well as phenomenological models). The modeling focus lies on the interactive behavior of different energy system components with varying complexity in the context of building energy supply, either thermal or electrical (i.e. electrical systems modeled using RMS values). Although the building itself can be modeled as a complex thermal and electrical energy consumer by using a number of thermal zones, a detailed thermal building simulation for different thermal conditions in one room, for example, requires a more specialized tool, like EnergyPlus (Green Building, for example, uses constant average temperatures in thermal zones).

With its specific focus on a wide range of energy system components, Green Building library significantly distinguish from other well-arranged Modelica Building libraries, like Modelica Buildings library (Wetter, 2009) which are more intended to accurately model building physics behavior. This way, Green Building became the tool of choice because this project's main aim was to compare different types of HVAC systems with less accuracy requirements on thermal building behavior.

\section{Building and HVAC System Modeling}

The developed basic greenhouse building model consists of 38 thermal zones, each represented by one Building Zone model of the Green Building library. These thermal zones individually represent each room in the planned greenhouse, 7 zones for the basement and 16 zones for the first floor of the social building as well as 15 zones for the glass-covered greenhouse section (12 cubicles, 3 corridors).

However, the basic Green Building models are optimized for calculation speed, providing a simplified set of equations to describe simple thermal behavior in a building zone (e.g. solar gains, ventilation losses, transmission losses through walls and windows, etc.). Therefore a hygrothermal building zone model was developed based on this basic model component.

The new model includes lighting and shading control depending on solar radiation as well as ventilation control depending on indoor humidity conditions. Furthermore, physical effects representing plant-specific hygrothermal behavior were added as well: 


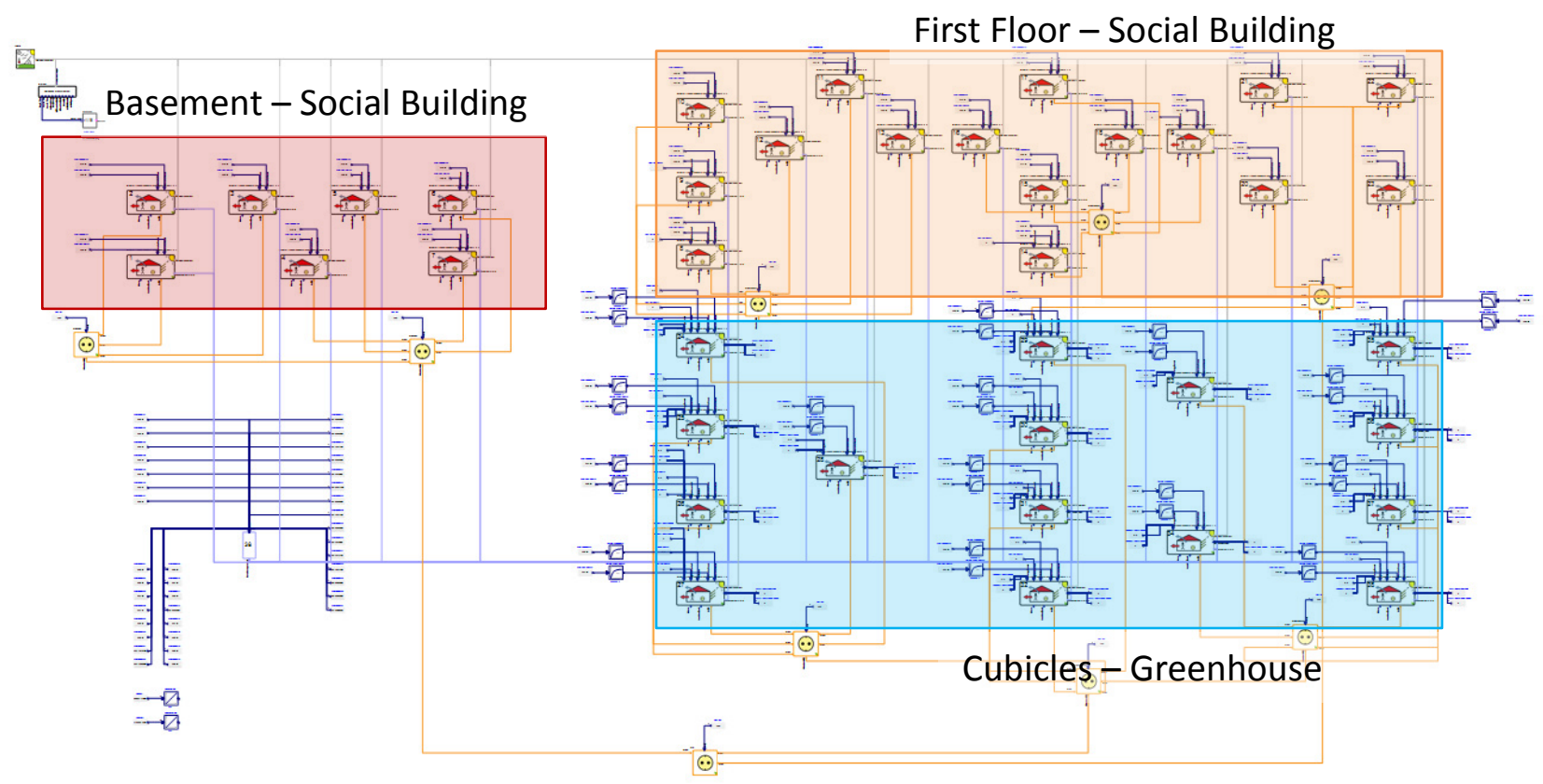

Figure 4: Building model of alternative greenhouse concept

- Evaporation heat of irrigation and humidification

- Condensation at cubicle walls and ceilings

- Transpiration of plants

- Ingress/input of moisture via persons

To compare both building concepts, the reference and the alternative building, two different building models were developed. Figure 4 shows the complete building model of the alternative building including all hygrothermal zones, weather conditions and grid as well as ventilation, lighting and shading control.

Each model additionally includes time schedules representing presence of research members in each zone (normally during the week between 8 a.m. and 6 p.m.) as well as electrical energy consumption via different relevant system components (e.g. refrigerators, server technology, autoclave, etc.).

The reference building model only uses additional lighting and ventilation control to keep required indoor temperature and humidity levels and to fulfill plantspecific lighting demand in each cubicle.

Furthermore, the alternative building model includes shading control for both planned energy screens. The first screen decreases solar irradiation in times of high indoor temperatures and second screen reduces heat losses via glass surfaces during night in times of low outdoor temperatures.

Both models only consider building physics, operation and hygrothermal behavior. There is no directly connected HVAC system model. However, the resulting time transient characteristics for heat, cold and electrical energy demand can further be used as input data sets for detailed HVAC systems simulation.

A direct link to the HVAC system models would be possible as well. However, the building model already runs about $24 \mathrm{~h}$ to simulate one year because of the required high accuracy regarding zoning, input data and analyzed physical effects (hygrothermal behavior). Because of relations between temperature control in each zone and available heat/cold from the HVAC system, linked models would increase simulation time to non-acceptable values.

This way, the HVAC system models are modeled separately. These models are again divided into heating and cooling system models. This is possible because building system simulation provides independent results for heat and cold demand. This approach further reduces simulation time.

Figure 5 shows the developed HVAC system model for cooling supply of the alternative building. Because of its structure, it can easily be compared to the original planner's system concept in Figure 2. All relevant components are individually modeled with existing or adapted Green Building model components.

However, Green Building library mainly considers heating system (e.g. Heat Pump, CHP) and electric components (e.g. batteries and eVehicles) as well as renewables (e.g. photovoltaics, solar thermal collectors). This way, some additional components based on Green Building modelling paradigms (Schwan et. al., 2011) had to be developed.

The main component of the cooling system concept is an absorption chiller. This component uses heat in internal chemical processes to produce cooling energy. This process is periodically reversed using external heat. Compared to conventional cooling systems, like chilled water units, the required amount of electricity can be significantly reduced. The absorption chiller model describes physical behavior based on a set of suitable pre-calculated operating points. This way full 


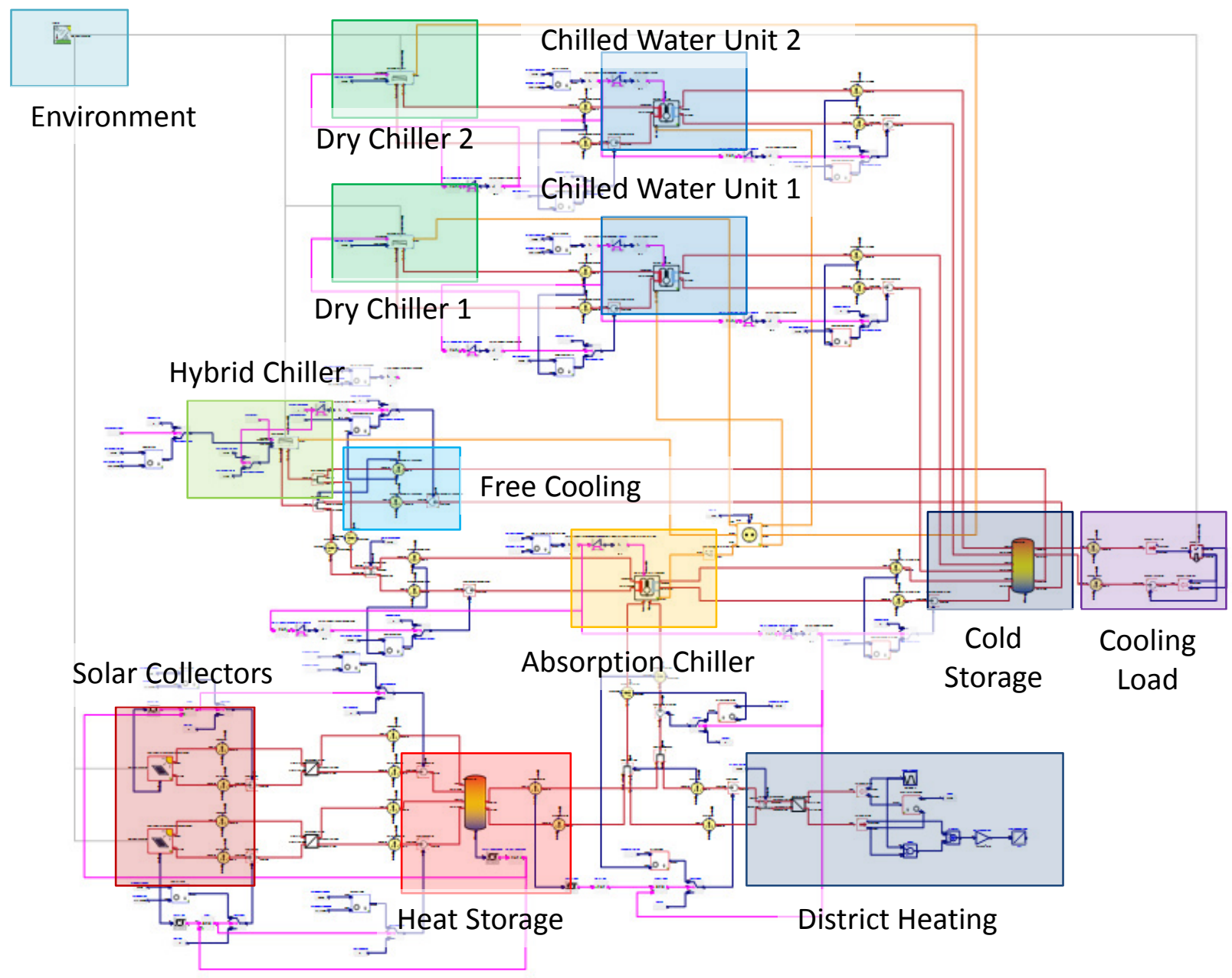

Figure 5: HVAC system model of alternative building (only cooling supply)

year simulations are possible, because the model runs very fast. Internal processes are transferred into a phenomenological behavior which is described as a black-box system.

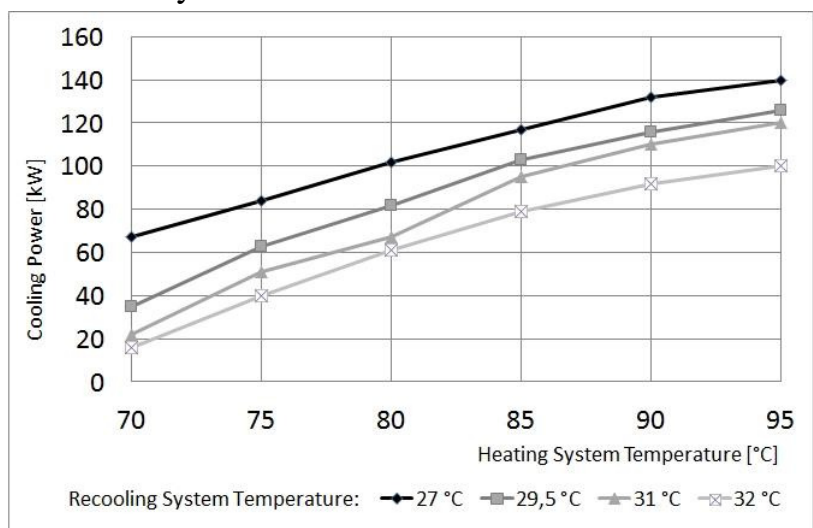

Figure 6: Sample characteristics of absorption chiller (Yazaki, 2015)

Basically, the new absorption chiller model has three interfaces to other system components, heating power input, recooling power output, and cooling power output. Each interface is divided into flow and return pipe with separate temperature levels but equal medium volume flow rate. The overall system behavior is simulated depending on the temperature difference between each flow and return as well as externally controlled volume flows. Heating power input and cooling power output are defined by linearly interpolated Modelica CombiTimeTables. These tables are directly filled with OEM-specific system data, e.g. cooling power characteristics shown in Figure 6.

This way, system validation was quite simple because internal processes were neglected and alternatively substituted by already validated data sheet values. A short set of simulation runs with constant input data sets (e.g. flow and return temperatures) proved developed model approach and showed the right system behavior at different characteristic operating points.

Another new model represents the phenomenological behavior of chilled water units. These system components produce cooling energy via external cooling and a certain amount of electrical energy. They mainly work as inverted heat pumps. This way, the newly developed chilled water unit model basically uses already existing Green Building Heat Pump functionality. However, the corresponding controllers are redesigned to use cold instead of heat demand as reference control value. Basic model layout 
and required tests are in accordance with previously presented absorption chiller model.

Both cooling system components require external coolers. Dry coolers only heat ambient air with heat from the cooling medium. Therefore, an external set of fans provide a specific amount of air to keep recooling temperature at a certain level.

Hybrid coolers additionally use evaporation heat of water to further cool down the cooling medium. They are especially needed in combination with absorption chillers because these components only work efficiently up to a maximum recooling temperature of $32^{\circ} \mathrm{C}$. Otherwise, absorption chillers would switch off just in times of highest cooling demand.

The overall HVAC system model in Figure 5 includes both the physical system behavior of relevant cooling system components as well as associated control algorithms:

- Priority control of solar heat supply for the absorption chiller (solar collector temperature greater than $78^{\circ} \mathrm{C}$ )

- Flow temperature control via district heating supply (absorption chiller temperature greater $75^{\circ} \mathrm{C}$ and smaller $95^{\circ} \mathrm{C}$ )

- Priority control of the cooling system (base load via the absorption chiller, peak load via the chilled water units)

- Integration of free cooling in times of low outdoor temperature via hybrid chiller

\section{Simulation Results}

The presented HVAC system design was developed using existing theoretical and empirical knowledge of greenhouse layout. The basic idea of the alternative building concept was to reduce overall energy consumption for heating and cooling about 50\% regarding the reference building concept.

However, solar aided cooling systems cannot be designed and calculated without adequate simulation models. The basic task of the system simulation was to validate both building concepts regarding intended energy saving potentials.

But before developed simulation models could be used to validate actual system concept, the models had to be validated regarding sufficient calculation results and relevant standards respectively tools. Therefore, the planner's original calculation results were used. The simulation results of greenhouse specific HORTEX 4.1 simulation tool (i.e. based on DIN EN ISO 13790 and DIN EN ISO 13789) showed an overall heating load of $287 \mathrm{~kW}$ for the reference and $196 \mathrm{~kW}$ for the alternative construction type. In comparison to that the simulation results of the developed Green Building models have been nearly at the same level (reference: 273 - $283 \mathrm{~kW}$, alternative: 194 - $201 \mathrm{~kW}$ depending on chosen operation strategy, c.f. Table 1 and Figure 7). This way, developed models can be used for further validation analysis.

The first simulation results only describe the effects of different building operation strategies regarding overall heat and cold demand. Basically, three different operation strategies were analyzed with both building models (c.f. Figure 4):

- V1: All-year high cooling requirements

- V2: Reduced cooling requirements during summer time

- V3: All-year reduced cooling requirements (maximum indoor cubicle temperature $25^{\circ} \mathrm{C}$ )

All three strategies mainly refer to cooling requirements of the twelve cubicles. The presented temperature levels (c.f. section 3) are always set as minimum temperature level for heating system control. But cooling system control can be different.

Table 1: Comparison of heat and cold demand

\begin{tabular}{l|cc} 
Variant & \multicolumn{1}{|c}{$\begin{array}{c}\text { Heat Demand } \\
{[\mathrm{MWh} / \mathrm{a}]}\end{array}$} & $\begin{array}{c}\text { Cold } \\
{[\mathrm{MWh} / \mathrm{a}]}\end{array}$ \\
\hline V1 Reference & 541.9 & 309.5 \\
V1 Alternative & 364.1 & 223.6 \\
savings & $\mathbf{3 2 . 8} \%$ & $\mathbf{2 7 . 8} \%$ \\
& & \\
V2 Reference & 532.7 & 140.0 \\
V2 Alternative & 355.0 & 106.8 \\
savings & $\mathbf{3 3 . 4} \%$ & $\mathbf{2 3 . 7} \%$ \\
& & \\
V3 Reference & 522.7 & 85.5 \\
V3 Alternative & 335.7 & 34.0 \\
savings & $\mathbf{3 5 . 8} \%$ & $\mathbf{6 0 . 2} \%$
\end{tabular}

Table 1 shows a short comparison between different simulation results of heat and cold demand for all three operation strategies and both building types as well as resulting saving potentials.

Because all three strategies do not affect the heating system control strategy, the resulting heat demand for all strategies is about the same. Small differences are caused by the inner heat storage capacity of the building.

Furthermore, the simulation results show that modern greenhouse glazing as well as extended shading and lighting control algorithms are not sufficient regarding desired energy savings.

However, different cooling system control strategies significantly affect the greenhouse's overall cooling demand. Table 1 shows that the higher cooling requirements reduce the energy saving potential of modern construction and control systems. If cooling demand is mainly caused by outer conditions (e.g. solar radiation, high outdoor temperatures - V3), these measures can reduce cooling demand about $60 \%$. If cooling energy is mainly used to provide cold in the evening when the cubicles have to be cooled down (c.f. section 3 ), saving potential is significantly lower. 


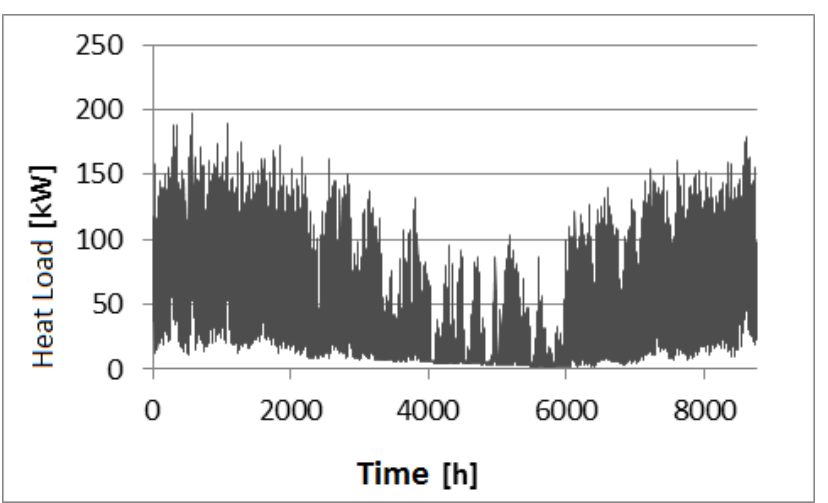

Figure 7: Heating load of alternative building and cooling strategy V1

Figure 7 and Figure 8 show the heating and cooling load curves with 15 minutes resolution which were calculated in the building simulation and are used as input data sets in following HVAC system simulation.

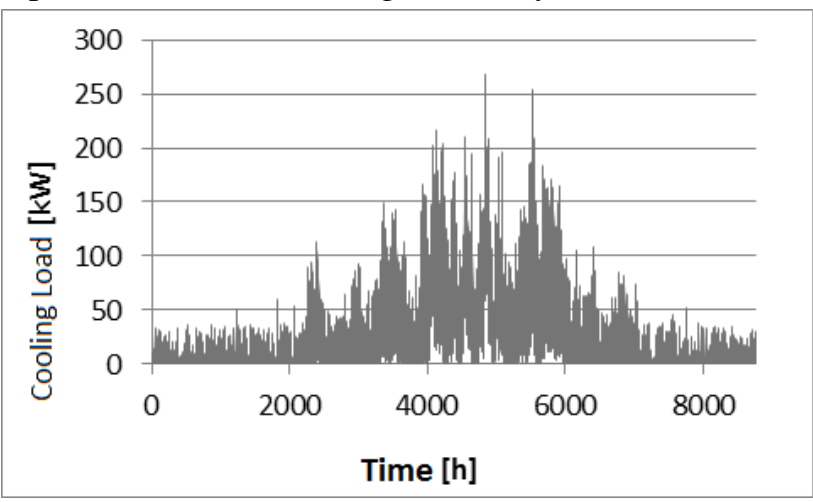

Figure 8: Cooling load of alternative building and cooling strategy V1

They are additionally used to proof HVAC system concept regarding individual components' requirements. Both characteristics represent worst-case scenarios for HVAC system operation, i.e. maximum heating and cooling load. Because the heat supply is covered by district heating, the required $200 \mathrm{~kW}$ heating power can easily be provided using a correctly dimensioned heat exchanger.

However, the maximum cooling power of HVAC system is mainly based on overall system characteristics. This way, the sum of the installed cooling power at suitable operating points of each component has to fulfill the total cooling power requirements in an adequate way. The overall installed cooling power in a worst-case-operating point (high recooling temperatures, low heating temperatures for absorption chiller) is about $215 \mathrm{~kW}$. Figure 8 indeed shows a maximum cooling power demand of about 270 $\mathrm{kW}$. However, this maximum cooling power is only required two or three times in a year and only for a few hours. Together with planned building internal cooling storage of $10 \mathrm{~m}^{3}$, the existing HVAC system concept should be able to fit all cooling requirements. Further system extensions are not necessary.
The final results of the simulations show that the alternative heating system concept can reduce overall ecological footprint about $68 \%$ in comparison to the reference system. This way $580 \mathrm{MWh}$ oil-based heating will be replaced by $363 \mathrm{MWh}$ from the district heating. Additionally, the specific carbon dioxide emissions are only half compared to the oil heating because the district heating system is heated by cogeneration power plants.

Evaluation of cooling system simulation requires more extensive analysis. The existing cooling system concept is divided into two parts, a high temperature (heat) part and a low temperature (cooling) part. Both parts are mainly connected via an absorption chiller.

The heat supply for absorption chiller is based on two different types of solar thermal collectors with an overall gross collector area of $194.7 \mathrm{~m}^{2}$. Both collectors provide about $65 \mathrm{MWh}$ heat over the whole year (55\% direct flow and $45 \%$ heat pipe collectors). The difference between the collectors results from different efficiency characteristics and a comparatively high minimum flow temperature of $75^{\circ} \mathrm{C}$.

The resultant solar collector utilization rate of 335 $\mathrm{kWh} / \mathrm{m}^{2}$ is quite good as normal rates are between 200 and $600 \mathrm{kWh} / \mathrm{m}^{2}$. On the one hand, the required high flow temperatures significantly reduce collector efficiency. On the other hand the cooling system's heat demand perfectly matches solar heat availability.

Both solar collectors provide heat to the connected $10 \mathrm{~m}^{3}$ heat storage. Figure 9 shows resultant heat storage temperatures over the whole year. Because of the comparatively low heat demand of the absorption chiller during the winter time heat storage temperatures partly exceed maximum temperatures of $95^{\circ} \mathrm{C}$. During these sunny winter days, solar collectors are shut down. This significantly reduces overall solar collector efficiency. Opposite to that solar heat is completely used by absorption chiller during summer time.

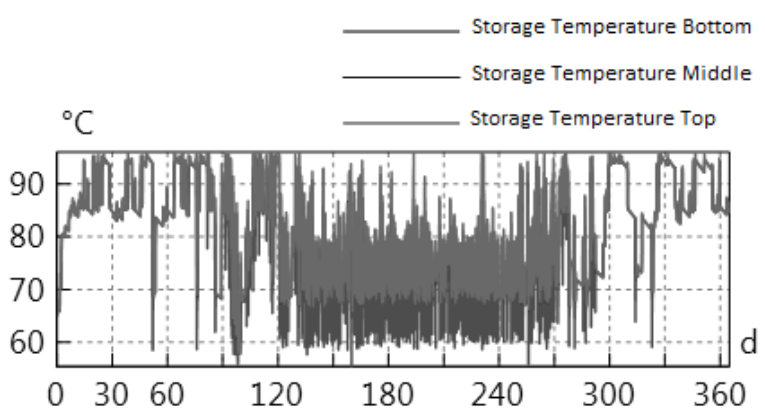

Figure 9: Simulated heat storage temperatures

Furthermore, Figure 9 shows a comparatively low temperature spread between bottom and top level of the storage tank. This behavior is caused by the storage tank mounted horizontally in the social building basement due to limited ceiling height of $3 \mathrm{~m}$. The low temperature spread further reduces solar collector and 
absorption chiller efficiency because of the high return temperatures and high required volume flow rates. An alternative storage configuration with several cascaded storage tanks will help to solve this problem.

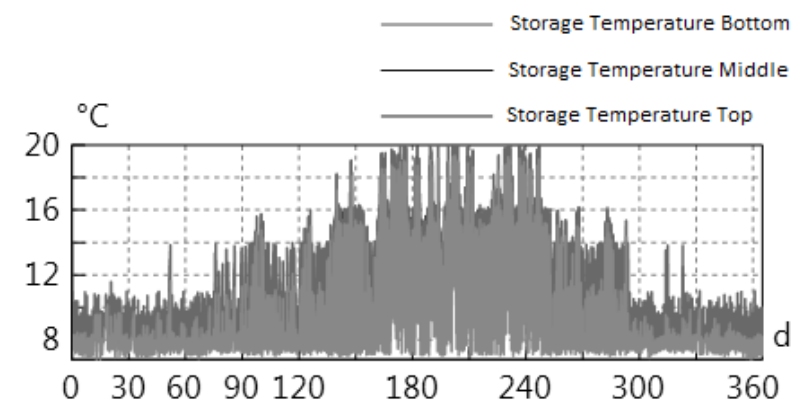

Figure 10: Simulated cooling storage temperature

The evaluated cooling system can provide enough cooling energy to keep cooling storage temperature at an adequate level (below $20^{\circ} \mathrm{C}$ ) over the whole year. In cold winter times free cooling provides almost all cooling energy.

The basic cooling energy demand is supplied by the absorption chiller over the whole year. In times of higher cooling demand both peak power chilled water units are successively switched-on. Further cooling energy peaks are compensated by a $10 \mathrm{~m}^{3}$ sized cooling storage.

Again, the temperature spread in cooling storage is comparatively low. This is for the same reason as for the heat storage, horizontal mounting. Again, a cascade solution can significantly improve that situation.

Finally, the simulation results were used to validate desired saving potentials of the alternative system concept versus the reference.

- Heat:
- Solar collectors:
$65 \mathrm{MWh} / \mathrm{a}$
- District heating:
$145 \mathrm{MWh} / \mathrm{a}$
- Absorption chiller:
$208 \mathrm{MWh} / \mathrm{a}$
- Free Cooling:
$19 \mathrm{MWh} / \mathrm{a}$
- Absorption chiller:
$159 \mathrm{MWh} / \mathrm{a}$
- CWU 1:
$41 \mathrm{MWh} / \mathrm{a}$
- CWU 2:
$5 \mathrm{MWh} / \mathrm{a}$

- Cold:

- Electrical energy:

$\begin{array}{lll}\circ \text { Absorption chiller: } & 0.8 \mathrm{MWh} / \mathrm{a} \\ \circ & \text { Hybrid cooler: } & 6 \mathrm{MWh} / \mathrm{a} \\ \circ & \text { CWU 1 + dry cooler: } & 13 \mathrm{MWh} / \mathrm{a} \\ \circ & \text { CWU 2 + dry cooler: } & 2 \mathrm{MWh} / \mathrm{a}\end{array}$

A priority control algorithm ensures that solar thermal collectors are mainly used to provide heat to the absorption chiller. However, the major heat demand is covered by the district heating because of the high regeneration temperature requirements of the chiller.

The alternative HVAC system concept mainly replaces high electrical energy consumption of the reference system (chilled water units) with a higher district heating consumption supported by solar energy. However, simulation results show an overall reduction of ecological footprint of about $51 \%$ for the alternative concept versus the reference. This way, the alternative system concept fulfills the desired energy saving potential.

\section{System Optimization}

The basic task of system simulation was to validate the building planner's concept of $50 \%$ reduction of ecological footprint. However, extensive analysis of the model and the results made further optimizations possible.

One of these system optimization approaches directly affects overall solar thermal collector efficiency. Figure 9 shows that heat storage temperature exceeds the maximum level of $95^{\circ} \mathrm{C}$ mainly in winter time. This reduces solar collector efficiency because the system has to be shut down. However, more heat is still needed inside the building during that time periods, e.g. to heat social building. The main idea of optimization is to use solar thermal collectors for both, heating and cooling.

To test the potential, the required heating system components were added to the cooling system. Simulation results show that solar collector gains increase about $27 \%$ in the described system configuration. That way, the overall collector utilization rate can be increased from $335 \mathrm{kWh} / \mathrm{m}^{2}$ to $432 \mathrm{kWh} / \mathrm{m}^{2}$, a tremendous improvement of system efficiency.

However, extended use of solar energy also for heating reduces cooling system performance because the additionally required heat is provided by district heating. Ecological footprint of cooling system is reduced to $48.5 \%$ in comparison to the reference concept. The overall energy saving potential thus only increases from $62.7 \%$ to $64 \%$ ( $70 \%$ for heating).

\section{Conclusion}

This paper describes an innovative approach to integrate building and HVAC system simulation with Modelica in ordinary building planning process.

As assistance to existing design processes, the simulation results help to validate the planners' ideas. Furthermore, modeling and simulation knowledge can be used to provide further system optimization.

Designing complex HVAC systems with an increasing share of renewables and storage systems is no viable without any kind of system simulation. With its interdisciplinary background and easy-tounderstand modeling approach, Modelica can help to 
improve future building planning process. The efficiency of this simulation approach makes it more and more suitable even for smaller sized projects.

For building simulation Modelica's most important benefits are the wide range of suitable model libraries, its capability in combining different physical domains in one mathematical model description, and nevertheless the easy-to-understand modelling paradigms. This way, Modelica can help to close the gap between no more suitable static building calculation and numerical system simulation in building systems engineering.

\section{Acknowledgements}

The presented modeling and simulation results were developed in closed co-operation with GEFOMA $\mathrm{GmbH}$ Großbeeren and Saxonian Real Estate and Construction Management, Public Company.

\section{References}

T. Schwan. Monitoring Concept and Validation of HVAC System Concept of Heat and Cold Supply for an Innovative Research Greenhouse in Leipzig. Project report, 2015.

GEFOMA Großbeeren GmbH. IDIV greenhouse construction in Leipzig. Planning documents, 2015.

VDI - Verein Deutscher Ingenieure. Cooling Load Calculation of Air-conditioned Rooms. VDI 2078 standard, 2007.

A. Bertram, D. Wilms, A. Bettig, R. Rehrmann. Increase of energy-efficiency of energy screens. Final report, University of Applied Sciences Osnabrück, 2004.

T. Schwan, R. Unger, B. Bäker, B. Mikoleit, C. Kehrer. Optimization of local renewable energy systems using automotive simulation approaches. $12^{\text {th }}$ Conference of International Building Performance Simulation Association, Sydney, 2011.

T. Schwan, R. Unger, B. Bäker, B. Mikoleit, C. Kehrer: Optimization-Tool for local renewable energy usage in the connected system: Building-eMobility; $8^{\text {th }}$ International Modelica Conference, Dresden, 2011.

T. Schwan, R. Unger, B. Bäker, B. Mikoleit, C. Kehrer, T. Rodemann: "Green Building" - Modelling renewable building energy systems and electric mobility concepts using Modelica, $9^{\text {th }}$ International Modelica Conference, Munich, 2012.

T. Schwan, R. Unger, C. Lerche, C. Kehrer: Model-Based Design of Integrative Energy Concepts for Building Quarters using Modelica. 10 ${ }^{\text {th }}$ International Modelica Conference, Lund, 2014.

T. Schwan, R. Unger: AUTOmoble EnergieArchitektur Final research project report. Dresden University of Technology, Dresden, 2013.

M. Wetter: A Modelica-based model library for building energy and control systems, $11^{\text {th }}$ International IBPSA Conference, Glasgow, 2009.

Yazaki: Data sheet of absorption chiller machine WFC-SC 30. Data sheet, 2015. 